\title{
Odorless Glutathione Microneedle Patches for Skin Whitening
}

\author{
Yechan Lee ${ }^{1}$, Sujeet Kumar ${ }^{1}$, Sou Hyun Kim ${ }^{2}$, Keum-Yong Seong ${ }^{1}$, Hyeseon Lee ${ }^{1}$, \\ Chaerin Kim ${ }^{1}$, Young-Suk Jung ${ }^{2, *}$ and Seung Yun Yang ${ }^{1, *}$ \\ 1 Department of Biomaterials Science, Life and Industry Convergence Institute, Pusan National University, \\ Miryang 50463, Korea; Yclee071@gmail.com (Y.L.), klempharma@gmail.com (S.K.), \\ ky.seong0124@gmail.com (K.-Y.S.), hyeslee96@gmail.com (H.L.), kimchaerin12@naver.com (C.K.) \\ 2 College of Pharmacy, Pusan National University, Busan 46241, Korea; hyunie1728@naver.com \\ * Correspondence: youngjung@pusan.ac.kr (Y.-S.J.); syang@pusan.ac.kr (S.Y.Y.); \\ Tel.: +82-51-510-2816 (Y.-S.J.); +82-55-350-5382 (S.Y.Y.)
}

Received: 31 December 2019; Accepted: 22 January 2020; Published: 27 January 2020

\begin{abstract}
Glutathione is a natural anti-aging substance that prevents the oxidation of protein thiols from reactive oxygen species. In the pharmaceutical industry, reduced glutathione (GSH) has been widely used for skin whitening due to its ability to inhibit tyrosinase. However, its poor permeability and foul odor limit its use in skin applications. Herein, we report a GSH-loaded dissolving microneedle (MN) patch prepared with hyaluronic acid (HA) that enables enhanced permeation across the skin and reduces the foul odor of GSH. HA was selected to prepare odorless GSH solutions and used for MN fabrications as a carrier of GSH. GSH-loaded MN (GSH-MN) arrays prepared from MN-forming solution containing up to $10 \%$ GSH showed good pattern uniformity and appropriate mechanical properties for insertion into the skin. The GSH-MNs with a loading capacity of $17.4 \%$ dissolve within 10 min following insertion into porcine skin and release the loaded GSH without being oxidized. This new approach combines functional biopolymers to reduce the characteristic GSH odor and advanced transdermal delivery based on $\mathrm{MN}$ technology to enhance skin permeation without pain. We believe this technique could expand the application of GSH in many cosmeceutical fields.
\end{abstract}

Keywords: glutathione; transdermal drug delivery; hyaluronic acid; microneedle; skin whitening

\section{Introduction}

Glutathione, a naturally occurring thiol tripeptide of $\gamma$-glutamyl-cysteinyl-glycine, plays a vital role in cellular redox reactions and is involved in the inhibition of melanin synthesis, protection from reactive oxygen species, and cell detoxification [1,2]. While glutathione is present in both oxidized and reduced forms within the body, reduced glutathione (GSH) is a compound with a high degree of biological utility [3,4]. For instance, its ability to suppress melanin synthesis through tyrosinase inhibition allows it to be used as a skin whitening agent in cosmeceuticals [5-7]. In addition, GSH may be used as an immune booster, an antidote for metal poisoning, and for the treatment of diseases such as fibrosis, glaucoma, and arthritis [8-11]. Unfortunately, its poor bioavailability and unpleasant odor limit the use of GSH in clinics despite its many therapeutic applications.

Medicinal peptides are commonly administered by parenteral routes using hypodermic needles. However, this route requires medical attention for each dose administration and has poor patient compliance due to the pain experienced during injection [12,13]. While topical applications have been used to deliver GSH across the skin, its foul odor and inability to pass through the stratum corneum (SC, the outermost barrier of skin) limit its use [14].

Recently, a minimally invasive system of transdermal delivery using microneedles (MNs) has received great attention from medical practitioners, particularly for the delivery of bioactive agents 
such as peptides and proteins that are labile to gastrointestinal $\mathrm{pH}$ and susceptible to enzymatic degradation [15].

To overcome the limitations associated with existing methods of GSH delivery, we envisioned a fast-dissolving MN patch prepared by deodorizing biopolymers to improve the efficacy of GSH and patient compliance. The high biocompatibility and tunable physicochemical properties of biopolymers such as hyaluronic acid (HA) render them suitable candidates as a MN material [16,17]. In addition, biopolymers with multifunctional groups can interact with molecules through reversible ionic interactions, hydrogen bonding, and van der Waal forces, thereby contributing to their high loading capacity and good adsorbent properties [18]. Since the release kinetics of drugs loaded in MNs may be controlled through dissolution or the degradation rate of the polymers used, dissolving MN platforms can be applied for the sustained and long-term release of drugs through transdermal routes [19-22].

Here, we report a new approach for the efficient and odorless transdermal delivery of GSH using dissolving MN patches prepared from deodorizable biopolymers. After screening several biopolymers for odorless GSH formulations, HA was selected as a material for the MN and used for the fabrication of GSH-loaded MN patches. The quantity of GSH loaded into the HA MNs was determined to have optimal anti-melanogenic effects and lower cytotoxicity, as confirmed from cytotoxicity and tyrosinase inhibition studies. The GSH-loaded HA MN (GSH-HA MN) arrays were evaluated for their uniform texture, geometry, desired mechanical strength, and skin-penetrating abilities. After the application of GSH-HA MN patches to animal skin tissue, their dissolving abilities and drug-releasing patterns were studied.

\section{Materials and Methods}

\subsection{Materials}

Reduced glutathione (GSH), gelatin (from porcine skin), 3-(4,5-dimethylthiazol-2-yl)-2,5diphenyltetrazolium bromide (MTT), and kojic acid (KA) was purchased from Sigma-Aldrich (St. Louis, MO, USA), sodium hyaluronate (100 k, HA) was purchased from SNVIA (Busan, Korea). Chondroitin sulfate (CS) was purchased from Wako Chemicals (Osaka, Japan). $\alpha$-Melanocyte stimulating hormone $(\alpha-\mathrm{MSH})$ was purchased from TOCRIS (Bristol, UK), and apoptosis detection kit using FITC (fluorescein isothiocyanate)-labeled annexin $\mathrm{V}$ was purchased from BD Biosciences (Bedford, MA, USA). A liquid prepolymer (Sylgard 184A) and a curing agent (Sylgard 184B) for the polydimethylsiloxane (PDMS) molding were purchased from Dow Corning (Midland, MI, USA). All chemicals were used without further purification. Porcine skin (hair removed) was procured from a local butcher shop and kept at $-20^{\circ} \mathrm{C}$ until it was used in experiments.

\subsection{Cell Culture}

Human keratinocytes (HaCaT cells) and mouse-derived melanoma cell lines (B16F10), which were used for in vitro studies, were obtained from ATCC (Manassas, VA, USA). Cells were grown in GSH-free DMEM medium (Hyclone, Logan, UT, USA), supplemented with $10 \%$ fetal bovine serum (FBS, Hyclone), $2 \mathrm{mM}$ glutamine (Sigma-Aldrich), $100 \mathrm{U} / \mathrm{mL}$ penicillin (Hyclone), and $100 \mathrm{ug} / \mathrm{mL}$ streptomycin (GenDEPOT, Barker, TX, USA) at $37{ }^{\circ} \mathrm{C}$ in a humidified atmosphere with $5 \% \mathrm{CO}_{2}$.

\subsection{Odor Tests}

The smell scoring method was performed to evaluate the reducing effect of biopolymers on the GSH odor [4]. The quantity of biopolymer (sodium hyaluronate, gelatin, and chondroitin sulfate) was fixed at $10 \%$ by weight in the total solution and GSH was mixed at different concentrations $(1.0 \%$, $2.0 \%, 2.5 \%$, and $5.0 \%$ by weight) in deionized (Di) water. After 30 min of mixing, a test panel of 10 volunteers smelled a solution containing a mixture of biopolymer and GSH. The GSH solution without a biopolymer was used as a reference to compare the sulfurous odor of the mixed samples. 
Each volunteer was asked to indicate their perception of the mixed solution's odor using the following 5-point scale: 1: no odor, 2: recognizable odor, 3: easily noticeable odor, 4: strong odor, and 5: intense odor.

\subsection{Gas Chromatography (GC) Measurements}

Based on scoring results, the amount of released $\mathrm{H}_{2} \mathrm{~S}$ was quantified for all GSH-HA formulations by gas chromatography (Shimadzu, Tokyo, Japan) using a Pulsed Frame Photometric Detector (PFPD) $[23,24]$. Solutions of $1 \%, 2.5 \%$, and 5\% (by weight) GSH was mixed with $10 \%$ (by weight) of $\mathrm{HA}$, and $1 \mathrm{~mL}$ was injected into a $10 \mathrm{~mL}$ brown vacuum vial. The vial was stored in an oven at $40^{\circ} \mathrm{C}$ for $1 \mathrm{~h}$ and then taken out. The generated gas $(100 \mu \mathrm{L})$ was collected using a syringe and injected into a Shimadzu GC equipped with a PFPD. The separation of the major sulfurous compounds was achieved on a $30 \mathrm{~m} \times 0.25 \mathrm{~mm}$ i.d. glass column (DB-1, J\&W) at $90{ }^{\circ} \mathrm{C}$ and a carrier flow (nitrogen) of $1 \mathrm{~mL} / \mathrm{min}$. The detection and injection temperatures were 250 and $150{ }^{\circ} \mathrm{C}$, respectively. The quantity of $\mathrm{H}_{2} \mathrm{~S}$ was measured using the standard samples. The sensitivity of the PFPD was $10 \mathrm{ppb}$ for $\mathrm{H}_{2} \mathrm{~S}$. The data of all samples were confirmed to be in the range of the standard curve.

\subsection{Cytotoxicity Tests}

Cytotoxicity of GSH was assessed using an MTT assay and annexin V-FITC staining. In brief, HaCaT cells (cell number: $1 \times 10^{4}$ ) were treated with $0.1,0.25,0.5$, and $1.0 \mathrm{mg} / \mathrm{mL}$ of GSH in DMEM media. After 24,48 , and $72 \mathrm{~h}$ of treatment, $50 \mu \mathrm{L}$ of MTT solution was added to the cell and incubated for $1 \mathrm{~h}$ before aspirating the medium. After that, $100 \mu \mathrm{L}$ of dimethyl sulfoxide (DMSO) was added and the percentages of viable cells were calculated by measuring the absorbance of $540 \mathrm{~nm}$ using a MULTISKAN GO reader (Thermo Scientific, Waltham, MA, USA). Apoptosis was measured by simultaneous staining with annexin V-FITC and propidium iodide $(\mathrm{PI})$. HaCaT cells $\left(1 \times 10^{6}\right)$ were treated with $0.1,0.25,0.5$, and $1.0 \mathrm{mg} / \mathrm{mL}$ of GSH. After $72 \mathrm{~h}$ treatment, cells were harvested, trypsinized, washed with cold PBS, and stained with $1 \mathrm{X}$ binding buffer containing annexin V-FITC solution and PI. Subsequently, cells were incubated at room temperature for $15 \mathrm{~min}$ in the dark. The stained cells were analyzed by flow cytometry within $1 \mathrm{~h}$. Both apoptotic and live cells were analyzed using a Becton Dickinson FACSscan flow cytometer and BD FACSDiva software (BD Biosciences, San Jose, CA, USA).

\subsection{Determination of Cellular Melanin Content and Tyrosinase Activity}

The proposed whitening effect of GSH was evaluated by measuring its ability to inhibit tyrosinase activity. In brief, mouse-derived B16F10 melanoma cells were seed in a 6-well culture plate at a concentration of $5.0 \times 10^{4}$ cells/well and allowed to attach overnight. Cells were treated with 0 (blank), $0.1,0.25,0.5$, and $1.0 \mathrm{mg} / \mathrm{mL}$ of GSH and $10 \mu \mathrm{M}$ of kojic acid (KA) as a positive control for $4 \mathrm{~h}$, and subsequently stimulated with $\alpha$-MSH $(1 \mu \mathrm{M})$ for $72 \mathrm{~h}$ to induce tyrosinase activity. After removing media, the cells were dissolved in $500 \mu \mathrm{L}$ of $1 \mathrm{~N} \mathrm{NaOH}$ and incubated for $1 \mathrm{~h}$ at $60{ }^{\circ} \mathrm{C}$ to solubilize melanin. The melanin content was determined by measurement of absorbance at $405 \mathrm{~nm}$. For tyrosinase activity, the cells were lysed in $100 \mu \mathrm{L}$ of $50 \mathrm{mM}$ sodium phosphate buffer ( $\mathrm{pH}$ 6.5) containing $5 \mu \mathrm{L}$ of $1 \%$ Triton $\mathrm{X}-100$ and $5 \mu \mathrm{L}$ of $0.1 \mathrm{mM}$ phenylmethylsulfonylfluoride. After centrifugation at 10,000 $\mathrm{g}$ (30 $\mathrm{min}, 4^{\circ} \mathrm{C}$ ), the supernatants with $20 \mu \mathrm{L}$ of L-3,4-dihydroxyphenylalanine (L-DOPA) were loaded to a 96-well plate, and absorbance was measured at $492 \mathrm{~nm}$ at $37^{\circ} \mathrm{C}$.

\subsection{Fabrication of GSH-MN Patches}

The bullet-shaped GSH-MN arrays $\left(10 \times 10 \mathrm{MNs} / \mathrm{cm}^{2}\right)$ were fabricated with a reusable PDMS mold by the solvent casting of aqueous solution of $10 \%$ HA solutions with different GSH concentrations $(0 \%$, $1.0 \%, 2.5 \%$, and $5.0 \%$ by weight). The negative PDMS molds with bullet-shaped cavities were replicated from metal MN arrays manufactured by micromachining [16]. MN-forming solutions (350 $\mu \mathrm{L}$ of $\mathrm{HA}$ or $\mathrm{HA} / \mathrm{GSH}$ solutions) were pipetted into the PDMS mold and dried at $40^{\circ} \mathrm{C}$ for $12 \mathrm{~h}$ following degassing under vacuum. The dried $\mathrm{MN}$ arrays were gently peeled off from the mold. The morphology of 
the fabricated MN arrays was characterized using digital (AM413ZT, Dino-Lite, Taiwan) and optical (Eclipse TS100, Nikon, Japan) microscopy. The HA MNs containing 0, 1, 2.5, and $5 \mathrm{mg} / \mathrm{mL}$ of GSH were referred to as $\mathrm{GSH}_{0}-\mathrm{HA} \mathrm{MN}, \mathrm{GSH}_{1}-\mathrm{HA} \mathrm{MN}, \mathrm{GSH}_{2.5}-\mathrm{HA} \mathrm{MN}$, and $\mathrm{GSH}_{5}-\mathrm{HA} \mathrm{MN}$, respectively.

\subsection{Fracture Tests}

A single HA MN and GSH-loaded HA MNs ( $\mathrm{GSH}_{0}-\mathrm{HA} \mathrm{MN}$, $\mathrm{GSH}_{1}-\mathrm{HA} \mathrm{MN}$, and $\mathrm{GSH}_{2.5}-\mathrm{HA} \mathrm{MN}$ ) were fixed using cyanoacrylate glue (Loctite 401, Loctite Corp, Dublin, Ireland) to pin the mounting stub placed on the lower grip of the universal testing machine (UTM, A\&D 5000H, A\&D Sales Corp, Daegu, Korea). The upper grip of the mechanical tester was moved axially down towards the MN tip at a rate of $0.1 \mathrm{~mm} / \mathrm{min}$. The yield force was measured as a function of the rate of probe displacement and expressed in Newtons $(\mathrm{N})$.

\subsection{Skin Insertion Test}

The skin insertion test was performed to check the penetrating ability of MNs, the probable extent of distortion, and possible tissue deflection during its insertion. The $\mathrm{GSH}_{0}-\mathrm{HA} \mathrm{MN}, \mathrm{GSH}_{1}-\mathrm{HA} \mathrm{MN}$, and $\mathrm{GSH}_{2.5}$-HA MNs were fixed with cyanoacrylate glue to the metallic surface via attachment with the upper grip of the UTM and inserted with a force of $10 \mathrm{~mm} / \mathrm{min}$ into excised porcine skin $\left(3 \times 3 \mathrm{~cm}^{2}\right.$, $\sim 2 \mathrm{~mm}$ thick) placed at the base of the mechanical tester [25]. The porcine skin was used after removing the subdermal fatty layer using a scalpel.

\subsection{Dissolution Test}

$\mathrm{GSH}_{2.5}$-HA MN was applied onto porcine skin $\left(3 \times 3 \mathrm{~cm}^{2}\right)$ at several predetermined time points (3, $5,7$, and $10 \mathrm{~min})$. After removing the MN patches, the dissolved height of the MN tips was measured using an optical microscope (Eclipse TS100, Nikon, Tokyo, Japan).

To confirm the punch mark of $\mathrm{GSH}_{2.5}$-HA MN patches, $0.5 \mathrm{mg}$ of dye (Rhodamine B) was added to $1 \mathrm{~mL}$ of $2.5 \%$ (by weight) mixed GSH solutions to prepare the MNs. Subsequently, MN array fabrication using a solution mixed with dye was manufactured using the same method described above. The punch mark formed from the $\mathrm{MN}$ arrays, their position during translation into the porcine skin, and degree of tissue deflection were analyzed under a digital microscope (AM413ZT, Dino-Lite, Taiwan). Any change in the morphology of the MN following insertion was examined under an optical microscope.

\subsection{Loading Capacity and Encapsulation Efficiency}

To determine the quantity of GSH loaded into the HA MNs, the MN tips from the $\mathrm{GSH}_{1}$-HA MN and $\mathrm{GSH}_{2.5}$-HA MN respectively, were cut and fully dissolved in PBS ( $\mathrm{pH}$ 7.4) for $24 \mathrm{~h}$. The quantity of GSH amount in the MN tips was determined by analyzing $10 \mu \mathrm{L}$ of sample solution using high-performance liquid chromatography (HPLC, e2695, Waters, USA) on a SunFire C18 column $(100 \AA, 5 \mu \mathrm{m}, 4.6 \times 250 \mathrm{~mm}$, Waters). The HPLC was operated using acetonitrile-water (5:95) and $0.1 \%$ trifluoroacetic acid (TFA) as a mobile phase with a flow rate of $0.8 \mathrm{~mL} / \mathrm{min}$. Based on HPLC data, the loading capacity (LC) and the encapsulation efficiency (EE) were calculated using the following equations:

$$
\begin{gathered}
\text { Loading capacity }(\%)=\frac{m_{e n}}{m_{t o t}} \times 100 \\
\text { Encapsulation Efficiency }(\%)=\frac{m_{e n}}{m_{\text {in }}} \times 100
\end{gathered}
$$

where, $m_{e n}$ represents the encapsulated drug amount in MN tips, $m_{t o t}$ is the total mass of MN tips, and $m_{\text {in }}$ represents the drug quantity in $\mathrm{MN}$-forming solutions [26]. 


\subsection{In Vitro GSH Skin Permeation Tests}

To investigate the ex vivo permeation kinetics across the skin of the reduced-GSH released from the $\mathrm{GSH}_{2.5}$-HA MN patches, static diffusion Franz cell tests were performed to calculate the rate of time-dependent GSH release through $\mathrm{GSH}_{2.5}-\mathrm{HA}$ MNs and its diffusion through the skin along with a reference GSH-HA solution. The $\mathrm{GSH}_{2.5}-\mathrm{HA} \mathrm{MN}$ patches and $350 \mu \mathrm{L} \mathrm{GSH}_{2.5}-\mathrm{HA}$ solution used for MN fabrications were applied on excised Sprague-Dawley (SD) rat skin ( $2 \mathrm{~mm}$ thick) placed between the donor and receptor chambers in the Franz diffusion cell, respectively. After inserting the $\mathrm{GSH}_{2.5}$-HA MN patches into the rat skin, a hydrocolloid adhesive patch (NeoDerm Roll, EVERAID, Yangsan, Korea) was applied to the MN backing during drug delivery. The receptor chamber with a side arm was filled with $22 \mathrm{~mL}$ of fresh PBS buffer ( $\mathrm{pH}$ 7.4) and maintained at $37^{\circ} \mathrm{C}$ [27]. One milliliter of sample was withdrawn at each time point $(0.5,1,2,4,8,12,24,36$, and $48 \mathrm{~h})$ from the Franz cell receptor chamber and refilled with an equal quantity of fresh PBS (pH 7.4). The $\mathrm{GSH}_{2.5}-\mathrm{HA} \mathrm{MN}$ patches were removed from rat skin after $1 \mathrm{~h}$. The quantity of GSH that was released from the MN tip and permeated through rat skin was analyzed by HPLC using the protocol described above. GSH was detected by measuring absorbance at $385 \mathrm{~nm}$ and the concentration of the drug was expressed in $\mathrm{mg}$.

\subsection{Statistical Analysis}

All results are expressed as the mean \pm standard deviation (SD) and analyzed using the Student's $t$-test. The level of significance was set at $p<0.05$.

\section{Results and Discussion}

\subsection{Screening Tests to Select Deodorizable Polymers}

Based on odor intensity, the scoring analysis was performed using a scale of 1-5 for evaluating the release of $\mathrm{H}_{2} \mathrm{~S}$ from the auto-degradation of free GSH and GSH-biopolymer formulations. The experiment was performed by including 10 randomly selected healthy volunteers of either sex. A strong odor was associated with a higher quantity of released $\mathrm{H}_{2} \mathrm{~S}$ and vice-versa. All concentrations (1.0-5.0\% by weight) of gelatin ( $4.75 \pm 0.2)$ and CS-GSH ( $3.25 \pm 0.95)$ formulations have scored higher while HA-GSH $(1.5 \pm 0.35)$ scored lower than GSH alone ( $2.75 \pm 0.61$; Figure 1a). The high scores for the gelatin-GSH and CS-GSH formulations compared to GSH alone was due to their characteristic odors in addition to the odor of the released $\mathrm{H}_{2} \mathrm{~S}$. Later, based on odor scores, the quantitative estimation of released $\mathrm{H}_{2} \mathrm{~S}$ (in ppm) was carried out by GC for the GSH-HA formulation at different concentrations. The amount of released $\mathrm{H}_{2} \mathrm{~S}$ was found to be at a minimum for $1.0 \%$ and $2.5 \%(0.55 \pm 0.01$ and $0.49 \pm 0.03 \mathrm{ppm})$ and at a maximum for $5.0 \%(1.03 \pm 0.01 \mathrm{ppm})$ of GSH in the formulation. At all concentrations, the values were found to be less than that of GSH alone $(0.59 \pm 0.03,0.75 \pm 0.04$ and $1.15 \pm 0.05$ for $1.0 \%, 2.5 \%$, and $5 \%$ of GSH, respectively; Figure $1 \mathrm{~b}$ ). The reason for this result was that the substituted $\mathrm{Na}^{+}$in HA reacts with the thiol group of GSH via the reaction formula shown in Supplementary Figure S1. It was confirmed that the reduction in odor was caused by the decreased production of $\mathrm{H}_{2} \mathrm{~S}$ (Supplementary Figure S1) $[28,29]$. These results show that HA has a better deodorant effect compared to gelatin and CS, which is why it was selected for the fabrication of $\mathrm{MNs}$ in the present study. Since the maximum deodorizing capacity of $\mathrm{HA}$ for released $\mathrm{H}_{2} \mathrm{~S}$ was observed with the $1.0 \%, 2.5 \%$, and $5.0 \%$ GSH-HA formulations (Figure 1b), these three concentrations were selected for fabricating MNs. 
(a)

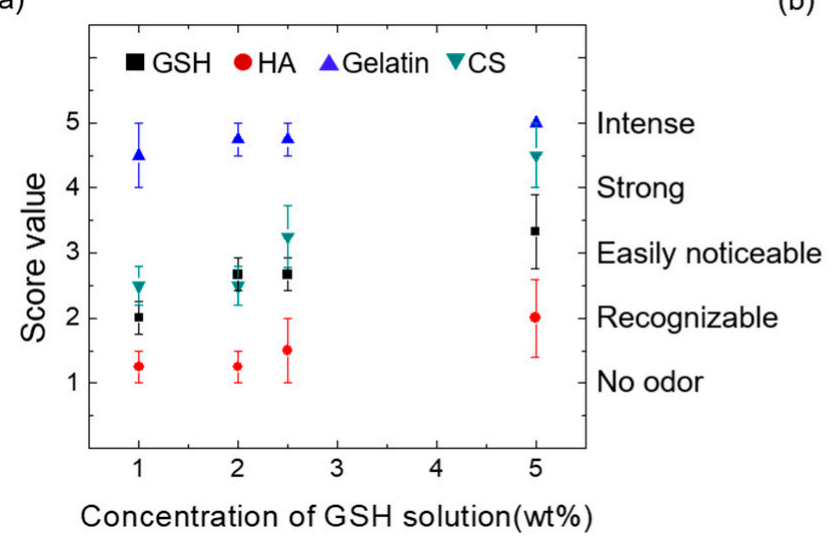

(b)

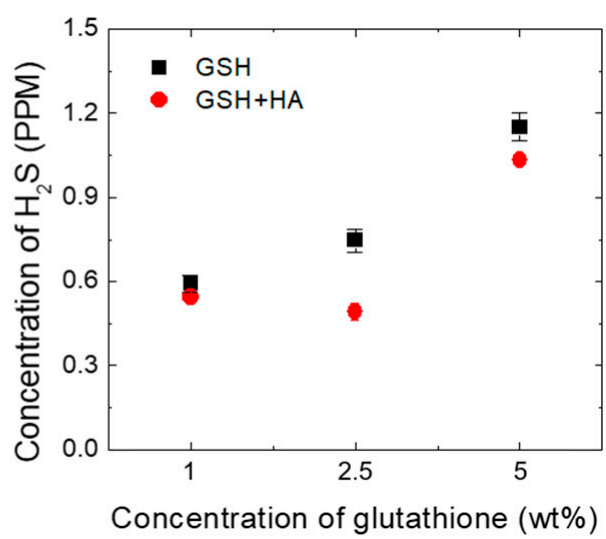

Figure 1. (a) Scoring analysis for odor test of reduced glutathione (GSH) and GSH-biopolymer formulations. Each volunteer $(n=10)$ was asked to indicate the perceived mixed solution odor intensity using the following 5-point scale: 1: no odor, 2: recognizable odor, 3: easily noticeable odor, 4: strong odor, and 5: intense odor. (b) Gas chromatography (GC) analysis of released $\mathrm{H}_{2} \mathrm{~S}$ from GSH and GSH-hyaluronic acid (HA) formulations by GC-flame photometric detector.

\subsection{Effect of GSH on Cytotoxicity and Tyrosinase Activity}

The MTT assay was used to determine whether GSH is cytotoxic to HaCaT. A fluorescence activated cell sorter (FACS) analysis was performed using annexin V, which specifically and strongly binds to cell surface PI in order to confirm whether apoptotic or necrotic cell death was observed [30]. Treatment with GSH $0.2-1.0 \mathrm{mg} / \mathrm{mL}$ did not significantly change the proportion of viable cells at $72 \mathrm{~h}$ compared to vehicle-treated cells (Figure 2a). No cytotoxic effects of GSH on the HaCaT cells were confirmed by flow cytometry analysis using annexin V. The exposure of HaCaT cells to $0,0.1,0.25,0.5$, or $1 \mathrm{mg} / \mathrm{mL}$ GSH for $72 \mathrm{~h}$ resulted in the concentration-dependent induction of apoptosis (Figure $2 \mathrm{~b}, \mathrm{c}$ ). Exposure to GSH did not cause a significant increase in apoptotic cells $(7.90 \pm 1.02-13.99 \pm 0.37 \%)$ and decrease in the proportion of live cells $(88.38 \pm 1.02-80.81 \pm 0.67 \%)$ compared to vehicle-treated cells $(4.85 \pm 0.72 \%$ and $90.47 \pm 0.93 \%$ for apoptotic and live cells respectively; Figure $2 b, c)$. These results suggest that GSH is not toxic to human keratinocytes and may be safely used on human skin.
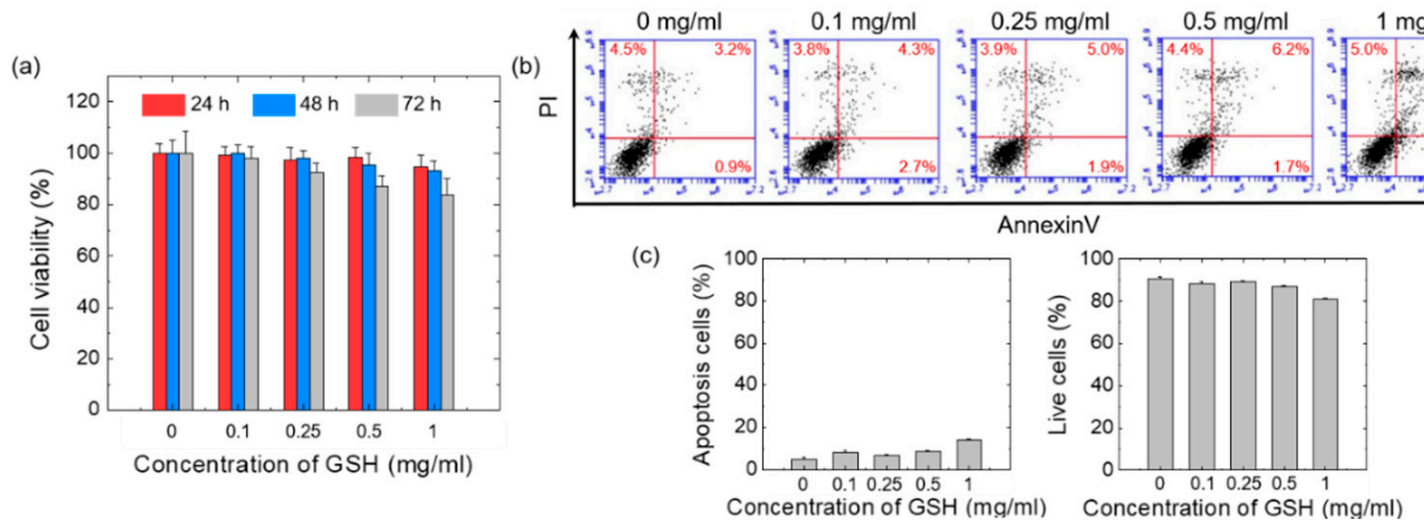

Figure 2. (a) MTT assay of GSH -treated HaCaT cells. (b) FACS analysis of propidium iodide (PI) uptake and annexin $\mathrm{V}$ binding in non-permeabilized cells (lower left, live cells; lower right, early apoptotic cells; upper right, late apoptotic cells, upper left, necrotic cells). The quantification of (c) apoptotic cells and live cells from three independent experiments.

Tyrosinase is the enzyme responsible for melanin synthesis. The whitening effects of GSH were evaluated by measuring the inhibition rate of both melanin production and activity of tyrosinase, the rate-limiting enzyme in melanogenesis. B16F10 cells were pre-treated with $10 \mu \mathrm{M} \mathrm{KA}$ and 
GSH (0.1-1.0 mg/mL) for $4 \mathrm{~h}$ and then stimulated with $\alpha-\mathrm{MSH}(1 \mu \mathrm{M})$ for $72 \mathrm{~h}$. GSH treatment significantly inhibited melanin production induced by $\alpha-\mathrm{MSH}$ (Figure 3a). In accordance with this finding, $\alpha$-MSH-induced tyrosinase activity (345.60 $\pm 18.29 \%$ of no GSH treatment) was significantly reduced to $207.34 \pm 2.78 \%$ in the treatment of $1 \mathrm{mg} / \mathrm{mL}$ GSH (Figure $3 \mathrm{~b}$ ).

(a)

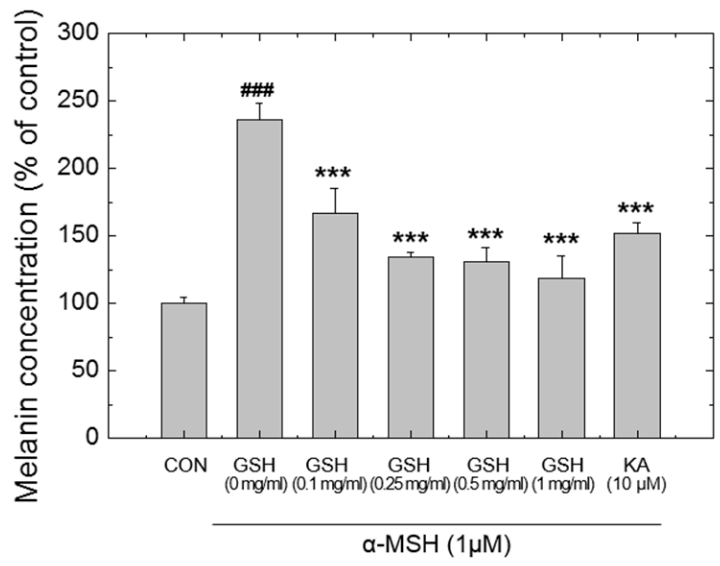

(b)

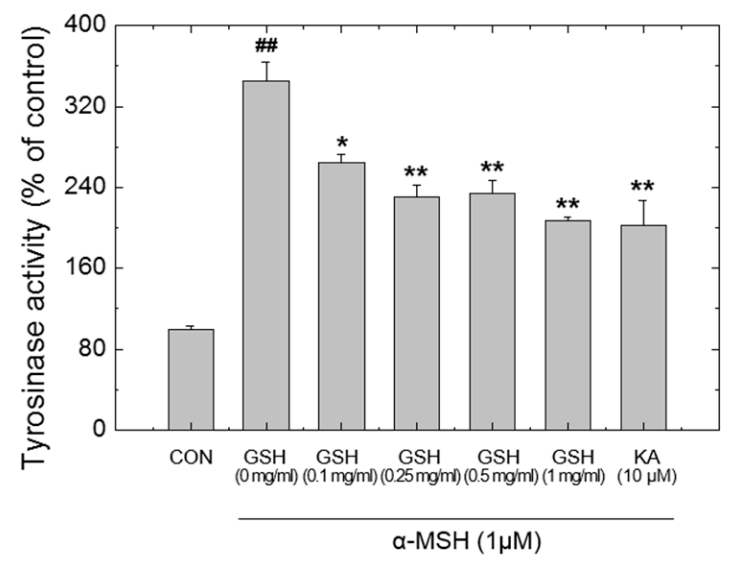

Figure 3. (a) Inhibitory effects of GSH and $\alpha$-MSH on melanin production in B16F10 cells. (b) Inhibitory effects of GSH and $\alpha$-MSH on tyrosinase activity. Kojic acid (KA) was used as a positive control. Each value represents the mean \pm standard deviation (SD) from triplicate experiments. (\#\#, \#\#, $p<0.01,0.001$, respectively. significant versus vehicle-treated; ${ }^{*}{ }^{* * *},{ }^{* * *} p<0.05,0.01,0.001$, respectively. significant versus $\alpha$-MSH alone).

\subsection{Fabrication of GSH-loaded HA MNs and Their Mechanical Properties}

To deliver GSH across the skin in a minimally invasive manner, we selected HA as an MN material based on its capacity to reduce $\mathrm{H}_{2} \mathrm{~S}$ that was confirmed from scoring tests and gas chromatographic data (Figure 1). The MN-forming solutions containing HA and GSH were used for the preparation of GSH-loaded HA MN (GSH-HA MN) arrays. The arrays were prepared via a solvent casting method using a PDMS mold having bullet-shaped cavities. The GSH-MN arrays $\left(100 \mathrm{MNs} / \mathrm{cm}^{2}\right)$ exhibited a uniform pattern with a height of $770 \pm 5 \mu \mathrm{m}$, base diameter of $172.25 \pm 2.5 \mu \mathrm{m}$, and a tip diameter of $7.8 \pm 2.5 \mu \mathrm{m}$ with an angle of $40 \pm 2.5^{\circ}$ (Figure $4 \mathrm{a}$ ). The geometry of $\mathrm{MN}$ was determined to ensure penetration of the SC layer and transdermal delivery of GSH with minimal vascular or neuronal damage to avoid pain and capillary bleeding at the application site. The uniform features of GSH-HA MNs were obtained when the MNs were prepared using MN-forming solutions containing 2.5\% GSH, but some bent MNs were observed when prepared with a high concentration (5\%) of GSH (Supplementary Figure S2).

The mechanical properties of GSH-HA MNs were examined in a compression mode. A single MN affixed with a cyanoacrylate glue on the bottom surface of UTM was axially compressed by a flat metal plate attached using the upper grip of the machine at the rate of $0.1 \mathrm{~mm} / \mathrm{min}$ (Figure $4 \mathrm{a}-\mathrm{c}$ ). The yield force, or the force required for a material to lose its elasticity, was determined to be 0.25 , 0.39 , and $0.40 \mathrm{~N}$ with a deviation of \pm 0.03 for $\mathrm{GSH}_{0}-\mathrm{HA} \mathrm{MNs}, \mathrm{GSH}_{1}-\mathrm{HA} \mathrm{MNs}$ and $\mathrm{GSH}_{2.5}-\mathrm{HA} \mathrm{MNs}_{\text {, }}$ respectively (Figure $4 \mathrm{~d}$ ). The insertion force was found to be $0.36 \pm 0.003,0.39 \pm 0.015$, and $0.37 \pm 0.005$ for $\mathrm{GSH}_{0}-\mathrm{HA} \mathrm{MNs}$, GSH $1-\mathrm{HA} \mathrm{MNs}$ and $\mathrm{GSH}_{2.5}-\mathrm{HA} \mathrm{MNs}$, respectively. Both the yield force and insertion force were found to be enough for the insertion of MNs into porcine skin without any fracture, distortion, or tissue deflection. 
(a)

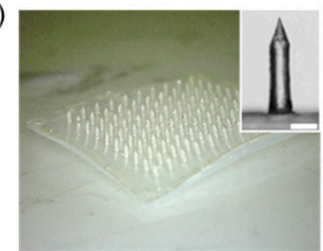

(d)

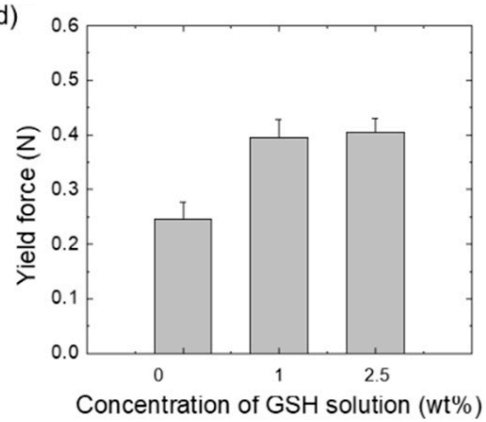

(b)

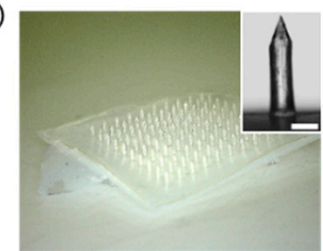

(e)

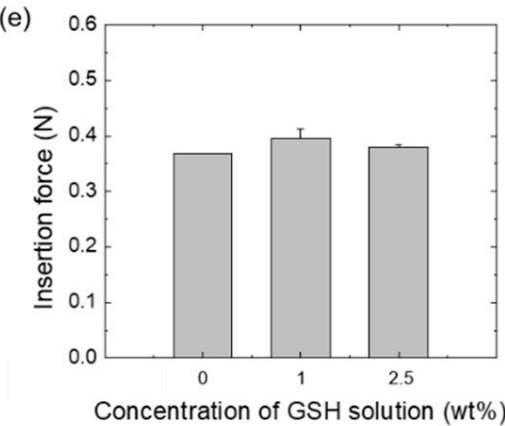

Figure 4. Photographs for (a) $\mathrm{GSH}_{0}-\mathrm{HA} \mathrm{MN}$, (b) $\mathrm{GSH}_{1}-\mathrm{HA} \mathrm{MN}$, and (c) $\mathrm{GSH}_{2.5}-\mathrm{HA} \mathrm{MN}$ patches prepared from HA solutions with different GSH concentrations ( $0 \%, 1 \%$, and $2.5 \%$, respectively). Scale bar $=200 \mu \mathrm{m}$. (d) Yield force and (e) insertion force of GSH-HA MNs.

\subsection{In Vitro Dissolution Tests of the GSH-HA MNs}

The dissolution time of a biopolymer determines the pattern of drug release and the onset of action for any formulation. To predict the time required for the release of $\mathrm{GSH}$, a single $\mathrm{MN}\left(\mathrm{GSH}_{2.5}-\mathrm{HA}\right)$ was inserted into porcine skin, which is structurally similar to human skin. Microscopic analysis showed the time-dependent dissolution of the MNs. After applying GSH-MNs to the skin for $12 \mathrm{~min}$, MN tips were completely dissolved, which initiated its pattern of rapid release (Figure $5 \mathrm{a}, \mathrm{b}$ ). To confirm skin penetration of the $\mathrm{GSH}_{2.5}$-HA MN patches, MN patches $(1.5 \times 1.5 \mathrm{~cm})$ loaded with rhodamine dye were applied to a porcine skin with an insertion force of $20 \mathrm{~N}$ for $1 \mathrm{~min}$. After removing the dye-loaded MN patches, we observed an array of dye spots corresponding to each needle, confirming the insertion of the $\mathrm{GSH}_{2.5}$-HA MNs into the skin (Figure 5c).

(a)

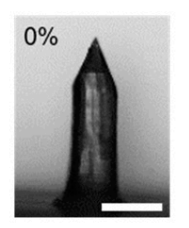

(b)

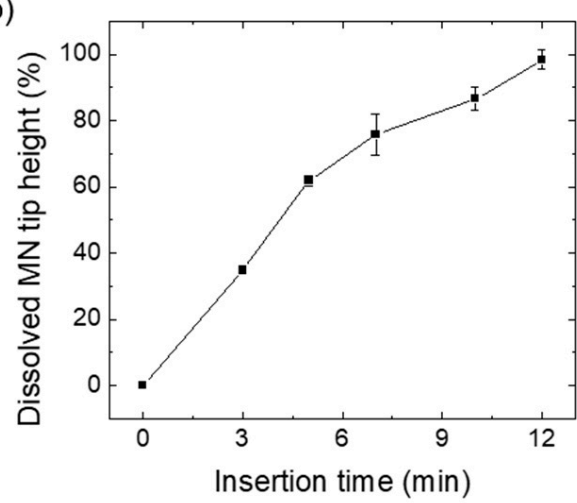

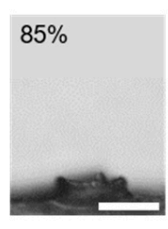

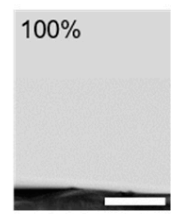

(c)

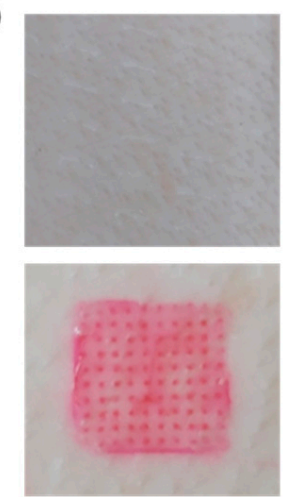

Figure 5. (a) Optical microscopic images of GSH-MN taken before ( $0 \%$ ) and after partial dissolution $(35 \%, 60 \%, 85 \%$, and $100 \%)$ of the MN tip following application into porcine skin (scale bar $=200 \mu \mathrm{m}$ ). (b) Plot for the dissolved tip height as a function of insertion time. (c) Photographic images showing the porcine skin before (top) and after (bottom) application of the dye-loaded GSH-MN patches. 
The loading capacity refers to the maximum amount of drug that can be subjected to a delivery carrier and determines its loading efficiency. The loading capacity of GSH-HA MN patches is defined as the mass of the loaded drug (GSH) in MN tips divided by the total mass of GSH-HA MN tips. To check the loading efficiency, GSH-loaded MN tips were cut and dissolved in PBS (pH 7.4), and the amount of GSH loaded into the tips was analyzed by HPLC. The loading amount of GSH in $100 \mathrm{MN}$ tips was $0.29 \pm 0.03 \mathrm{mg}$ and $0.56 \pm 0.03 \mathrm{mg}$ for $\mathrm{GSH}_{1}-\mathrm{HA} \mathrm{MN}$ patches and $\mathrm{GSH}_{2.5}-\mathrm{HA} \mathrm{MN}$ patches, respectively. Given the total mass of GSH-MN tips (100 MNs, $2 \pm 0.2 \mathrm{mg}$ ), the loading capacity was $11.26 \pm 1.24 \%$ and $21.33 \pm 1.13 \%$ while the encapsulation efficiency was found to be $8.36 \pm 0.92 \%$ and $6.34 \pm 0.34 \%$ for $\mathrm{GSH}_{1}$-HA MN and $\mathrm{GSH}_{2.5}-\mathrm{HA} \mathrm{MNs}$, respectively (Table 1). Similar values between the HA:GSH weight ratio (10:1 or 10:2.5) in MN-forming solutions and the loading capacity of GSH in $\mathrm{MN}$ patches suggest the uniform distribution of GSH in the MN patch.

Table 1. Amount of GSH loaded in GSH-HA MN patches.

\begin{tabular}{cccc}
\hline $\begin{array}{c}\text { GSH-Loaded } \\
\text { MN Patch }\end{array}$ & $\begin{array}{c}\text { GSH Amount Loaded in } \\
\text { 100 MN Tips (mg) }\end{array}$ & $\begin{array}{c}\text { Loading Capacity of } \\
\text { GSH (\%) }\end{array}$ & $\begin{array}{c}\text { Encapsulation Efficiency of } \\
\text { GSH (\%) }\end{array}$ \\
\hline $\mathrm{GSH}_{1}$-HA MN & $0.29 \pm 0.03$ & $11.26 \pm 1.24$ & $8.36 \pm 0.92$ \\
$\mathrm{GSH}_{2.5}$-HA MN & $0.56 \pm 0.03$ & $21.33 \pm 1.13$ & $6.34 \pm 0.34$ \\
\hline
\end{tabular}

\subsection{Ex Vivo Skin Permeation Test of GSH-HA MN Patches}

To estimate the onset as well as the duration of GSH release from $\mathrm{GSH}_{2.5}-\mathrm{HA} \mathrm{MNs}$, the Franz cell study was performed for $48 \mathrm{~h}$ by placing the skin of a SD rat under simulated physiological conditions (Figure 6). The $\mathrm{GSH}_{2.5}$-HA MNs showed relatively fast linear release kinetics for the initial $12 \mathrm{~h}$ followed by a slow rate of release over time.

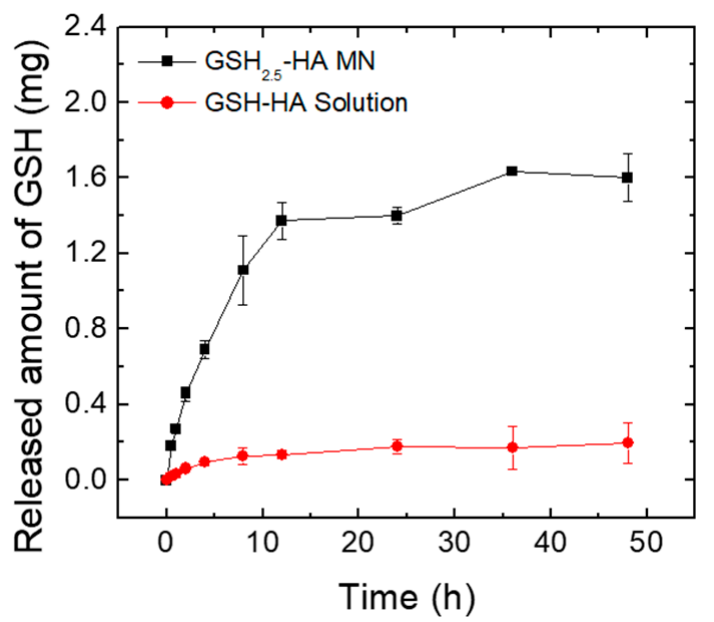

Figure 6. In vitro release profiles of GSH from $\mathrm{GSH}_{2.5}-\mathrm{HA} \mathrm{MN}$ patches and $\mathrm{GSH}_{2.5}-\mathrm{HA}$ solution analyzed by the Franz cell assay.

The permeated GSH amount across skin after MN application was $\sim 1.4 \mathrm{mg}$ for the initial $12 \mathrm{~h}$ of the experiment and reached to $\sim 1.6 \mathrm{mg}$ for $48 \mathrm{~h}$. A quantity of GSH greater than the loaded amount in MN tips was delivered. This amount not only includes the GSH loaded in the $\mathrm{GSH}_{2.5}-\mathrm{HA}$ MN tips but also the GSH incorporated in the base layer as a drug reservoir. In contrast, the GSH-HA solution was slowly delivered in small amounts $(\sim 0.2 \mathrm{mg})$ due to poor skin permeation of GSH. As transdermal delivery of human growth hormone using MNs prepared by carboxymethylcellulose and trehalose demonstrated a short $t_{\max }(\sim 30 \mathrm{~min})$ after $\mathrm{MN}$ application and exhibited similar pharmacokinetic profiles with that of the SC injection [19], the GSH-HA patch with fast water-absorption properties would be applicable for systemic GSH delivery. Based on in vitro study, the treatment of $1 \mathrm{mg} / \mathrm{mL}$ 
GSH significantly inhibited melanin production and tyrosinase activity. Considering the small volume $\left(\sim 150 \mu \mathrm{L} / \mathrm{cm}^{2}\right)$ of interstitial fluid in skin [31], locally delivered GSH by HA MN patches (1.6 mg GSH/1 $\mathrm{cm}^{2} \mathrm{MN}$ patch) could act as an antioxidant agent during the MN dissolution process. Since the release kinetics of GSH loaded in MNs can be controlled by the crosslinking density of the MN material [32,33], a swellable MN platform would be beneficial for effective GSH delivery with minimal side effects.

\section{Conclusions}

Based on the deodorizing capacity (score value) and results of GC, we selected HA to develop biodegradable MN patches for odorless transdermal delivery of GSH. HA masked the foul odor of GSH more efficiently than gelatin and CS. The HA-MNs patch $\left(\mathrm{GSH}_{2.5}-\mathrm{HA}\right)$ had enough durability to penetrate through the skin without being damaged. The release of GSH from the HA-MNs patches $\left(\mathrm{GSH}_{1}-\mathrm{HA}\right.$ and $\mathrm{GSH}_{2.5}-\mathrm{HA}$ ) was found to be uniform over a given time period, as shown by respective experiments. The cytotoxic and tyrosinase inhibitory studies showed GSH concentration of $1 \mathrm{mg} / \mathrm{mL}$ to be safe and effective for skin whitening purposes. Altogether, the feasibility of the developed HA MN patches as a promising platform for transdermal delivery of GSH or drugs with noxious or unacceptable organoleptic properties has been demonstrated based on experimental data claimed in this study.

Supplementary Materials: The following are available online at http://www.mdpi.com/1999-4923/12/2/100/s1, Figure S1: The effect of sodium hyaluronate on odor reduction, Figure S2: $\mathrm{GSH}_{5}-\mathrm{HA} \mathrm{MN}$ array images.

Author Contributions: Conceptualization, Y.L., Y.-S.J. and S.Y.Y.; Methodology, Y.L., S.H.K., K.-Y.S., and S.K.; Data curation, C.K., and H.L.; Writing — original draft, Y.L., S.K., S.Y.Y.; review and editing, S.K., Y.-S.J., K.-Y.S. and S.Y.Y.; Supervision, S.Y.Y. All authors have read and agreed to the published version of the manuscript.

Funding: This research was supported by the National Research Foundation of Korea (NRF) funded by the Ministry of Science and ICT (NRF-2018R1A4A1025623), and by the National Creative Research Initiative Program through the National Research Foundation of Korea (NRF) funded by the Ministry of Science, ICT and Future Planning (NRF-2017R1D1A3B03035360).

Conflicts of Interest: S.Y.Y. is an inventor of a patent licensed to the company (SNVIA) developing odorless GSH cosmetic products. This potential conflict of interest is managed by Pusan National University.

\section{References}

1. Forman, H.J.; Zhang, H.; Rinna, A. Glutathione: Overview of its protective roles, measurement, and biosynthesis. Mol. Asp. Med. 2009, 30,1-12. [CrossRef]

2. Hayes, J.D.; McLellan, L.I. Glutathione and glutathione-dependent enzymes represent a co-ordinately regulated defence against oxidative stress. Free Radic. Res. 1999, 31, 273-300. [CrossRef]

3. Rahman, I.; Kode, A.; Biswas, S.K. Assay for quantitative determination of glutathione and glutathione disulfide levels using enzymatic recycling method. Nat. Protoc. 2006, 1, 3159. [CrossRef]

4. Yano, H. Comparison of Oxidized and Reduced Glutathione in the Bread-Making Qualities of Rice Batter. J. Food Sci. 2012, 77, C182-C188. [CrossRef] [PubMed]

5. Weschawalit, S.; Thongthip, S.; Phutrakool, P.; Asawanonda, P. Glutathione and its antiaging and anti-melanogenic effects. Clin. Cosmet. Investig. Dermatol. 2017, 10, 147. [CrossRef] [PubMed]

6. Villarama, C.D.; Maibach, H.I. Glutathione as a depigmenting agent: An overview. Int. J. Cosmet. Sci. 2005, 27, 147-153. [CrossRef] [PubMed]

7. Arjinpathana, N.; Asawanonda, P. Glutathione as an oral whitening agent: A randomized, double-blind, placebo-controlled study. J. Dermatol. Treat. 2012, 23, 97-102. [CrossRef] [PubMed]

8. Droge, W.; Breitkreutz, R. Glutathione and immune function. Proc. Nutr. Soc. 2000, 59, 595-600. [CrossRef] [PubMed]

9. Patrick, L. Mercury toxicity and antioxidants: Part 1: Role of glutathione and alpha-lipoic acid in the treatment of mercury toxicity. Altern. Med. Rev. 2002, 7, 456-472.

10. Chen, J.Z.; Kadlubar, F.F. A new clue to glaucoma pathogenesis. Am. J. Med. 2003, 114, 697-698. [CrossRef]

11. Hassan, M.Q.; Hadi, R.A.; Al-Rawi, Z.S.; Padron, V.A.; Stohs, S.J. The glutathione defense system in the pathogenesis of rheumatoid arthritis. J. Appl. Toxicol. 2001, 21, 69-73. [CrossRef] [PubMed] 
12. Seong, K.Y.; Seo, M.S.; Hwang, D.Y.; O'Cearbhaill, E.D.; Sreenan, S.; Karp, J.M.; Yang, S.Y. A self-adherent, bullet-shaped microneedle patch for controlled transdermal delivery of insulin. J. Control. Release 2017, 265, 48-56. [CrossRef] [PubMed]

13. Jin, J.; Zhu, L.L.; Chen, M.; Xu, H.M.; Wang, H.F.; Feng, X.Q.; Zhu, X.P.; Zhou, Q. The optimal choice of medication administration route regarding intravenous, intramuscular, and subcutaneous injection. Patient Prefer. Adherence 2015, 9, 923-942. [PubMed]

14. Bouwstra, J.A.; Honeywell-Nguyen, P.L.; Gooris, G.S.; Ponec, M. Structure of the skin barrier and its modulation by vesicular formulations. Prog. Lipid Res. 2003, 42, 1-36. [CrossRef]

15. Jiskoot, W.; Randolph, T.W.; Volkin, D.B.; Middaugh, C.R.; Schöneich, C.; Winter, G.; Friess, W.; Crommelin, D.J.; Carpenter, J.F. Protein instability and immunogenicity: Roadblocks to clinical application of injectable protein delivery systems for sustained release. J. Pharm. Sci. 2002, 101, 946-954. [CrossRef]

16. Liu, S.; Jin, M.N.; Quan, Y.S.; Kamiyama, F.; Katsumi, H.; Sakane, T.; Yamamoto, A. The development and characteristics of novel microneedle arrays fabricated from hyaluronic acid, and their application in the transdermal delivery of insulin. J. Control. Release 2012, 161, 933-941. [CrossRef]

17. Wang, C.; Ye, Y.; Hochu, G.M.; Sadeghifar, H.; Gu, Z. Enhanced cancer immunotherapy by microneedle patch-assisted delivery of anti-PD1 antibody. Nano Lett. 2016, 16, 2334-2340. [CrossRef]

18. Dassanayake, R.S.; Acharya, S.; Abidi, N. Biopolymer-based materials from polysaccharides: Properties, processing, characterization and sorption applications. In Advanced Sorption Process Applications; Edebali, S., Ed.; IntechOpen: London, UK, 2018; pp. 1-24.

19. Lee, J.W.; Choi, S.O.; Felner, E.I.; Prausnitz, M.R. Dissolving microneedle patch for transdermal delivery of human growth hormone. Small 2011, 7, 531-539. [CrossRef]

20. Donnelly, R.F.; Singh, T.R.R.; Garland, M.J.; Migalska, K.; Majithiya, R.; McCrudden, C.M.; Kole, P.L.; Mahmood, T.M.T.; McCarthy, H.O.; Woolfson, A.D. Hydrogel-forming microneedle arrays for enhanced transdermal drug delivery. Adv. Funct. Mater. 2012, 22, 4879-4890. [CrossRef]

21. Kim, J.D.; Kim, M.; Yang, H.; Lee, K.; Jung, H. Droplet-born air blowing: Novel dissolving microneedle fabrication. J. Control. Release 2013, 170, 430-436. [CrossRef]

22. Kim, H.; Seong, K.Y.; Lee, J.H.; Park, W.; Yang, S.Y.; Hahn, S.K. Biodegradable microneedle patch delivering antigenic peptide-hyaluronate conjugate for cancer immunotherapy. ACS Biomater. Sci. Eng. 2019, 5, 5150-5158. [CrossRef]

23. Du, X.; Song, M.; Rouseff, R. Identification of new strawberry sulfur volatiles and changes during maturation. J. Agric. Food Chem. 2011, 59, 1293-1300. [CrossRef] [PubMed]

24. Boczkaj, G.; Kaminski, M.; Przyjazny, A. Process control and investigation of oxidation kinetics of postoxidative effluents using gas chromatography with pulsed flame photometric detection (GC-PFPD). Ind. Eng. Chem. Res. 2010, 49, 12654-12662. [CrossRef]

25. Davis, S.P.; Landis, B.J.; Adams, Z.H.; Allen, M.G.; Prausnitz, M.R. Insertion of microneedles into skin: Measurement and prediction of insertion force and needle fracture force. J. Biomech. 2004, 37, 1155-1163. [CrossRef] [PubMed]

26. Chandrasekharan, A.; Hwang, Y.J.; Seong, K.Y.; Park, S.; Kim, S.; Yang, S.Y. Acid-treated water-soluble chitosan suitable for microneedle-assisted intracutaneous drug delivery. Pharmaceutics 2019, 11, 209. [CrossRef] [PubMed]

27. Kim, B.; Seong, K.Y.; You, I.; Selvaraj, V.; Yim, S.G.; O'Cearbhaill, E.D.; Jeong, U.; Yang, S.Y. Touch-actuated transdermal delivery patch for quantitative skin permeation control. Sens. Actuators B Chem. 2018, 256, 18-26. [CrossRef]

28. Jensen, G.A.; Adams, D.F.; Stern, H. Absorption of hydrogen sulfide and methyl mercaptan from dilute gas mixtures. J. Air Pollut. Control Assoc. 1966, 16, 248-253. [CrossRef]

29. Onda, K.; Takeuchi, H.; Kobayashi, T.; Yokota, K. Simultaneous Absorption of Hydrogen Sulphide and Carbon Dioxide in Aqueous Sodium Hydroxide Solutions. J. Chem. Eng. Jpn. 1972, 5, 27-33. [CrossRef]

30. Kabakov, A.E.; Gavai, V.L. Cell death and survival assays. In Chaperones; Humana Press: New York, NY, USA, 2018; pp. 107-127.

31. Samant, P.P.; Prausnitz, M.R. Mechanisms of sampling interstitial fluid from skin using a microneedle patch. Proc. Natl. Acad. Sci. USA 2018, 115, 4583-4588. [CrossRef] 
32. Yang, S.Y.; O'Cearbhaill, E.D.; Sisk, G.C.; Park, K.M.; Cho, W.K.; Villiger, M.; Bouma, B.E.; Pomahac, B.; Karp, J.M. A bio-inspired swellable microneedle adhesive for mechanical interlocking with tissue. Nat. Commun. 2013, 4, 1702. [CrossRef]

33. Migdadi, E.M.; Courtenay, A.J.; Tekko, I.A.; McCrudden, M.T.; Kearney, M.C.; McAlister, E.; McCarthy, H.O.; Donnelly, R.F. Hydrogel-forming microneedles enhance transdermal delivery of metformin hydrochloride. J. Control. Release 2018, 285, 142-151. [CrossRef] [PubMed]

(C) 2020 by the authors. Licensee MDPI, Basel, Switzerland. This article is an open access article distributed under the terms and conditions of the Creative Commons Attribution (CC BY) license (http://creativecommons.org/licenses/by/4.0/). 